\title{
The correlation between Ro-52 antibody and interstitial lung disease in dermatomyositis
}

\section{Xiaojing Xing ( $\nabla$ xingxiaojing1985@163.com )}

Chinese PLA General Hospital https://orcid.org/0000-0002-6567-5581

\section{Anqi Li}

Chinese PLA General Hospital

\section{Yonghong Hao}

Chinese PLA General Hospital

Chengxin Li

Chinese PLA General Hospital

\section{Research article}

Keywords: Dermatomyositis, Antibody Ro-52, Interstitial lung disease

Posted Date: February 11th, 2020

DOI: https://doi.org/10.21203/rs.2.23195/v1

License: (c) (i) This work is licensed under a Creative Commons Attribution 4.0 International License. Read Full License 


\section{Abstract}

Background Recent studies have shown that Ro-52 antibody is associated with interstitial lung disease(ILD) in children with dermatomyositis(DM) and with the degree of disease severity. Moreover, we found that $50 \%$ or more cases of adult patients with DM tested positive for antibody Ro-52. Here, we analyzed the correlation between antibody Ro-52 and ILD in inpatients with DM. Objective To explore the correlation between Ro-52 antibody and ILD of DM.

Methods A total of 153 patients with DM were collected, who met the classification criteria of idiopathic inflammatory myositis. Immunoblotting was used to detect 16 myositis-specific autoantibodies (MSAs) and myositis-associated autoantibodies (MAAs) from patient serum samples. High-resolution computed tomography (HRCT) was used to calculate the ILD severity score, and the tumors were screened. The clinical data and CT scores were analyzed retrospectively.

Results Our data showed that antibodies of Ro-52 and MDA5 were risk factors for ILD development in patients with DM. Antibody Ro-52 was the most commonly occurring (52.9\%) antibody in DM patients. The presence of Ro-52 in DM patients strongly suggested the possibility for the occurrence of ILD (86.4\%). The severity of Ro-52-positive cases was higher than that of the Ro-52-negative cases.Ro-52 may increase the incidence of ILD when combined with other antibodies of PM-Scl75, PM-Scl100, TIF1$\gamma, \mathrm{Mi}-2 \beta$, and MDA5.

Conclusions The occurrence of ILD is highly likely in patients with DM having the antibody Ro-52. Thus, Ro-52 is a risk factor for ILD in DM.

\section{Background}

Dermatomyositis (DM) is an autoimmune connective tissue disease involving the skeletal system, muscle, skin, lungs, and other organs. It is mainly manifested through symmetrical inflammatory myopathy of the proximal extensors of the extremities and specific skin lesions. DM has a high mortality rate and the main factors affecting its prognosis include secondary infection, interstitial lung disease (ILD), and malignant tumors [1]. Previous studies suggest the incidence of ILD in DM is 19.9-78\% [2]. Recent studies have found that myositis-specific autoantibodies (MSAs) and myositis-associated autoantibodies (MAAs) have a certain predictive value in DM prognosis [3]. For example, antibody human transcription intermediary factor $1 \gamma$ (anti-TIF1- $\gamma$ ) is closely related to adult DM with malignant tumors [4-5]. Anti-melanoma differentiation-related gene 5 (Anti-MDA5) antibody is expressed with DM patients, who with rapidly progressive ILD and has a high mortality [6]. Anti-Histidyl-transfer (t) RNA synthetase antibody was found in $15-30 \%$ of patients with DM who were more prone to ILD [7]. Recent studies have shown that antibody Ro-52 is associated with ILD in children with DM, and with the degree of severity of the disease [8]. Our group also found that nearly $50 \%$ of adult patients with DM tested positive for antibody Ro-52. This study will analyze the correlation between antibody Ro-52 and ILD in DM inpatients at the first medical center of PLA General Hospital, from 2016 to date. 


\section{Methods}

\section{Patients}

Our study retrospectively collected all DM patients in the inpatient department, from March 1, 2016 to September 30, 2019, at the first medical center of PLA General Hospital, Beijing, China. A total of 153 DM patients with TIF1Y antibody were selected and analyzed. All the patients met the classification criteria of idiopathic inflammatory myositis (IIMs) in 2017- EULAR/ACR [9], excluding polymyositis, the overlap syndrome, inclusion body myositis and muscular dystrophy, metabolism-related myopathy, and drugrelated myopathy and the patients whose age at onset $<18$ years.

\section{Clinical data collection}

The age and sex, follow up time, main symptoms, important physical signs, and abnormal laboratory indicators included lactate dehydrogenase (LDH), creatine kinase (CK). Complications included tumors and ILD. High-resolution computed tomography (HRCT) was used to confirm ILD, and the tumors were screened using serum tumor markers, systemic superficial lymph node ultrasound, abdominal enhancement magnetic resonance imaging (MRI), nasopharyngeal endoscopy, gynecological ultrasound, gastrointestinal endoscopy, and/or systemic positron emission tomography-computed tomography (PET-CT) . Sixteen types and level of MSAs and MAAs were collected: MAAs (including antibodies PMScl75, PM-Scl100, SRP, Ku, and Ro-52); Histidyl-transfer (t)RNA synthetase antibody (including antibodies Jo-1, PL-7, PL-12, EJ, and OJ); MSAs (including antibodies MDA-5, TIF1- $\gamma$, NXP2, Mi-2a, Mi-2 $\beta$, and SAE1).

This study was approved by the Research and Ethical Review Committees of PLA General Hospital. Informed consent was obtained from all the patients and/or their parents, according to the Declaration of Helsinki.

\section{Serum sample and methods}

Patient serum samples available for autoantibody testing at the time of enrolment were included in the study. Sixteen MSAs and MAAs were detected via immunoblotting. Serum $(15 \mu \mathrm{L})$ was taken from each patient and diluted uniformly with $1.5 \mathrm{~mL}$ sample buffer. The numbered side of the test strip was placed upside down in the incubator, and $1.5 \mathrm{~mL}$ sample buffer was added into each incubator, incubated on the shaking bed at room temperature $\left(18-25^{\circ} \mathrm{C}\right)$ for $5 \mathrm{~min}$, and then, the liquid in the incubator was 
absorbed and the diluted serum samples were added into the incubator. After incubating at room temperature for $30 \mathrm{~min}$, the film strips were cleaned three times with $1.5 \mathrm{~mL}$ buffer solution, for $5 \mathrm{~min}$ each time. Then, the diluted enzyme conjugate (anti-IgG labeled with alkaline phosphatase) was added to the incubator. After incubation at room temperature for $30 \mathrm{~min}$, the buffer was cleaned three times with $1.5 \mathrm{~mL}$, for $5 \mathrm{~min}$ each time. Then, the substrate solution $(1.5 \mathrm{~mL})$ was added in the incubator. After incubation at room temperature for 10 min on a rocking bed, the film strips were cleaned three times with distilled water, for one minute each time. Finally, the test strip was placed in the result determination template, and the result was judged by visual inspection or using the EUROLineScan program (3.2.1) after air drying.

\section{ILD severity score in patients with DM}

HRCT score: The classical six-point method was used to calculate the HRCT score, as described below. The lung structure was divided into six regions: upper left, upper right, middle left, middle right, lower left, and lower right. The upper region was the tracheal carina, the lower region was the pulmonary vein, and the rest was the middle lung. Pulmonary structural changes and scores included: (1) attenuation of normal signals, with a score of 1 ; (2) ground glass changes without bronchiectasis, with a score of 2 ; (3) consolidation without bronchiectasis, with a score of 3; (4) ground glass changes with bronchiectasis, with a score of 4 ; (5) consolidation with bronchiectasis; (6) alteration of lung honeycomb, with a score of 6. The six regions were independent of each other, with $5 \%$ as the unit. The range of abnormal images involving the lungs was estimated separately, and then multiplied by the corresponding scores. Next, the average of the six regions was taken as the final HRCT score of the patients [10]. Finally, the scores for normal HRCT $=0$, minor change ILD $=0-1$, moderate change ILD $=1-3$, and severe change ILD $=3-6$. Two specialists, who have been engaged in imaging work for 5 years, completed the evaluation of HRCT, and the HRCT scores of these two doctors were averaged.

\section{Statistical analysis}

For binary data group comparisons, $\chi^{2}$ or Fisher's exact tests were used. Comparisons of continuous data were made using the Student's t-test. Risk factors were analyzed via logistic regression. The relationship between ILD severity and antibody Ro-52 was analyzed using the nonparametric method. A $P$-value < 0.05 was considered significant.

\section{Results}

\section{Patient characteristics}


This study retrospectively analyzed 153 DM patients from March 1, 2016 to September 30, 2019 at the inpatient department of the first medical center of PLA General Hospital, Beijing, China. ILD was detected in 81 (52.9\%; ILD presence group) and undetected in 72 (47.1\%; ILD absence group) patients, and both the groups had more female than male patients. There was no significant difference in the ratio of men to women between both the groups $(P=0.757)$. Regardless of the age at the onset or age at inclusion of $D M$ the patients in ILD presence group were not significant with the patients in the absence group $(P=0.114$ and $P=0.072$, respectively). Meanwhile, the median age of the entire DM cohort was 48 years. There was no difference in the incidence of ILD between patients over and under the age of $48(P=0.675)$. In the follow-up time, there was no difference between in ILD presence group and ILD absence group ( $P=$ $0.903)$, the follow-up time were more than 1.5 years. Dysphagia and myalgia are common clinical manifestations in DM patients. Our data showed that patients in the ILD-absence group were more prone to dysphagia $(P=0.000)$ and patients in the ILD-presence group were more prone to myalgia $(P=0.046)$. Elevated LDH $(P=0.234)$ and CK $(P=0.603)$ did not differ significantly between the ILD-absence and presence groups. There is no relationship between ILD and malignant tumor $(P=0.175)$. Among the sixteen kinds of MSAs and MAAs, there were significant differences in the antibodies Ro-52 $(P=0.000)$, EJ $(P=0.030)$, TIF1- $\gamma(P=0.049)$, Mi-2a $(P=0.001)$, MDA5 $(P=0.002)$, indicating that these antibodies may be important factors associated with ILD development (Table 1 ). 
Patient characteristics of 153 DM patients stratified by ILD

\begin{tabular}{|c|c|c|c|c|}
\hline Patient Characteristic & ILD & & $\begin{array}{l}\mathrm{P} \text { - } \\
\text { value }\end{array}$ & Total/Positive(\%) \\
\hline Total & $\begin{array}{l}\text { Absence }(\mathrm{N}= \\
72)\end{array}$ & $\begin{array}{l}\text { Presence }(\mathrm{N}= \\
81)\end{array}$ & & 157 \\
\hline Male/Female & $23 / 49$ & $24 / 57$ & 0.757 & $47 / 106$ \\
\hline Age at onset, mean (SD), years & $42.34 \pm 12.33$ & $45.54 \pm 12.46$ & 0.114 & $48.24 \pm 13.54$ \\
\hline $\begin{array}{l}\text { Age at inclusion, mean (S.D.), } \\
\text { years }\end{array}$ & $47.35 \pm 12.70$ & $51.27 \pm 13.83$ & 0.072 & $49.45 \pm 13.42$ \\
\hline Age > 48 year(N/Y) & $38 / 34$ & $40 / 41$ & 0.675 & $78 / 75$ \\
\hline $\begin{array}{l}\text { Follow up time, mean (S.D.), } \\
\text { years }\end{array}$ & $1.92 \pm 1.77$ & $1.88 \pm 2.03$ & 0.903 & $1.90 \pm 1.90$ \\
\hline Dysphagia (N), $n(\%)$ & $36(50 \%)$ & $17(21 \%)$ & 0.000 & $53(34.6 \%)$ \\
\hline Myalgia (N), n(\%) & $64(89 \%)$ & $62(76.5 \%)$ & 0.046 & $126(82.4 \%)$ \\
\hline Malignant tumor (N), n(\%) & $9(12.5 \%)$ & $5(6.2 \%)$ & 0.175 & $14(9.2 \%)$ \\
\hline Elevated CK (N), n(\%) & $29(40.3 \%)$ & $36(40.3 \%)$ & 0.603 & $65(42.5 \%)$ \\
\hline Elevated LDH(N), n(\%) & $46(63.9 \%)$ & $59(72.8 \%)$ & 0.234 & $107(68.9 \%)$ \\
\hline Antibody Ro-52 (N), n(\%) & $11(15.3 \%)$ & $70(86.4 \%)$ & 0.000 & $81(52.9 \%)$ \\
\hline Antibody PM $\square$ Scl100 (N), n(\%) & $3(4.2 \%)$ & $4(4.9 \%)$ & 1.000 & $7(4.6 \%)$ \\
\hline Antibody PM $\square$ Scl75 (N), n(\%) & $3(4.2 \%)$ & $9(11.1 \%)$ & 0.196 & $12(7.8 \%)$ \\
\hline Antibody SRP (N), n(\%) & $6(8.3 \%)$ & $12(14.8 \%)$ & 0.214 & $18(11.8 \%)$ \\
\hline Antibody Ku(N), n(\%) & $4(5.6 \%)$ & $5(6.2 \%)$ & 1.000 & $8(5.9 \%)$ \\
\hline Antibody Jo-1 (N), n(\%) & $4(5.6 \%)$ & $10(12.3 \%)$ & 0.241 & $14(9.2 \%)$ \\
\hline Antibody PL-7 (N), n(\%) & $5(6.9 \%)$ & $8(9.9 \%)$ & 0.516 & $13(8.5 \%)$ \\
\hline Antibody PL-12 (N), n(\%) & $1(1.4 \%)$ & $3(3.7 \%)$ & 0.698 & $4(2.6 \%)$ \\
\hline Antibody EJ (N), n(\%) & $0(0 \%)$ & $6(7.4 \%)$ & 0.030 & $6(3.9 \%)$ \\
\hline Antibody OJ (N), n(\%) & $0(0 \%)$ & $2(2.5 \%)$ & 0.498 & $2(1.3 \%)$ \\
\hline Antibody TIF1- $\gamma(\mathrm{N}), \mathrm{n}(\%)$ & $20(27.8 \%)$ & $12(14.8 \%)$ & 0.049 & $37(20.9 \%)$ \\
\hline Antibody Mi-2a(N), n(\%) & $9(12.5 \%)$ & $0(0 \%)$ & 0.001 & $9(5.9 \%)$ \\
\hline Antibody $\mathrm{Mi}-2 \beta(N), n(\%)$ & $8(11.1 \%)$ & $9(11.1 \%)$ & 1.000 & $17(11.1 \%)$ \\
\hline
\end{tabular}




\begin{tabular}{|lllll|}
\hline Patient Characteristic & ILD & & $\begin{array}{l}\text { P- } \\
\text { value }\end{array}$ & Total/Positive(\%) \\
\hline Antibody MDA-5(N), $\mathrm{n}(\%)$ & $9(12.5 \%)$ & $27(33.3 \%)$ & 0.002 & $36(23.5 \%)$ \\
\hline Antibody SAE-1(N), $\mathrm{n}(\%)$ & $1(1.4 \%)$ & $2(2.5 \%)$ & 1.000 & $3(2.0 \%)$ \\
\hline Antibody NXP-2(N), $\mathrm{n}(\%)$ & $13(18.1 \%)$ & $7(8.6 \%)$ & 0.085 & $20(13.1 \%)$ \\
\hline All antibody negative(N), $\mathrm{n}(\%)$ & $12(16.7 \%)$ & $0(0 \%)$ & -- & $12(7.8 \%)$ \\
\hline
\end{tabular}

Logistic regression analysis to test the influence factors of ILD

Then, we used dysphagia, myalgia, and antibodies Ro-52, EJ, Mi-2a, TIF1- $\gamma$ and MDA5 as logistic regression variables in determining the factors influencing ILD in the $153 \mathrm{DM}$ patients. The antibodies Ro52 and MDA5 were found to be risk factors for ILD development $(O R=42.411, P=0.000 ; O R=28.757, P=$ 0.045 ; respectively), while, dysphagia was protective factors for ILD $(O R=0.182, P=0.005)$, and myalgia, antibodies EJ, TIF1- $\gamma$ and Mi-2a were not correlated with ILD formation $(\mathrm{OR}=1.040 \mathrm{E}+10, \mathrm{P}=0.999 ; \mathrm{OR}=$ $0.261, P=0.100$ and $O R=0.000, P=0.999$, respectively) (Table 2).

Table 2

Logistic regression analysis to test the influence factors of ILD

\begin{tabular}{|llll|}
\hline Variables & OR & $95 \% \mathrm{Cl}$ & P-value \\
\hline Dysphagia & 0.182 & $0.055-0.607$ & 0.005 \\
\hline Myalgia & 0.454 & $0.171-2.202$ & 0.493 \\
\hline Antibody Ro-52 & 42.411 & $13.568-140.999$ & 0.000 \\
\hline Antibody EJ & $1.040 \mathrm{E}+10$ & $0.000-$ & 0.999 \\
\hline Antibody TIF1- $\gamma$ & 0.261 & $0.261-0.070$ & 0.100 \\
\hline Antibody Mi-2a & 0.000 & $0.000-$ & 0.999 \\
\hline Antibody MDA-5 & 28.757 & $2.266-3.719$ & 0.045 \\
\hline
\end{tabular}

The difference of ILD in Ro-52 antibody negative or positive

The incidence of MSAs, MAAs, and ILD-positive cases among the 153 DM patients are shown in Table 1. Twelve (7.8\%) patients were all negative for the antibodies, and none of these twelve patients was diagnosed with ILD. Fourteen (9.2\%) patients expressed antibody Ro-52 while testing negative for the other antibodies, and 12 among these 14 patients had ILD. 127 patients co-expressed two or more of MSA- and/or MAA-positive. The highest rate of MSA- and MAA-positives was found in $81(52.9 \%)$ out of all the patients, for antibody Ro-52, and 70 (86.4\%) out of these 81 patients had ILD. Meanwhile, 14 were Ro-52 single antibody-positive, and the other 67 (82.7\%) co-expressed with one or more other MSAs 
and/or MAAs (Tables 1). Since $82.7 \%$ of the patients expressed Ro-52 combined with other antibodies, it was necessary to determine whether Ro-52 is an independent risk factor for ILD. Therefore, we analyzed the difference in ILD between other MSA- and MAA- antibody combined with and without the Ro-52 antibody. Our results showed that Ro-52 did increase the incidence of ILD when combined with the other antibodies, for antibodies of PM-Scl75, PM-Scl100, TIF1- $\gamma$, Mi-2 $\beta$ and MDA5 $(P=0.018, P=0.029, P=$ $0.005, \mathrm{P}=0.008, \mathrm{P}=0.008$; respectively ) (Table 3 ).

Table 3

The difference of ILD in Ro-52 antibody negative or positive

\begin{tabular}{|llll|}
\hline Positive antibodies & \multicolumn{2}{l}{ ILD(-)/ILD(+) } & P-value \\
\hline Total & Ro-52(-) & Ro-52(+) & \\
\hline Antibody PM $\square$ ScI75 & $3 / 1$ & $0 / 8$ & 0.018 \\
\hline Antibody PM $\square$ Scl100 & $3 / 0$ & $0 / 4$ & 0.029 \\
\hline Antibody SRP & $5 / 3$ & $1 / 9$ & 0.065 \\
\hline Antibody Ku & $3 / 1$ & $1 / 4$ & 0.330 \\
\hline Antibody Jo-1 & $4 / 3$ & $0 / 7$ & 0.070 \\
\hline Antibody PL-7 & $4 / 1$ & $1 / 7$ & 0.065 \\
\hline Antibody PL-12 & $1 / 0$ & $0 / 3$ & 0.250 \\
\hline Antibody EJ & $0 / 1$ & $0 / 5$ & 0.622 \\
\hline Antibody OJ & $0 / 0$ & $0 / 2$ & -- \\
\hline Antibody TIF1- $\gamma$ & $15 / 2$ & $5 / 10$ & 0.005 \\
\hline Antibody Mi-2a & $8 / 0$ & $1 / 0$ & - \\
\hline Antibody Mi-2 $\beta$ & $7 / 1$ & $1 / 8$ & 0.008 \\
\hline Antibody MDA-5 & $8 / 1$ & $1 / 26$ & 0.000 \\
\hline Antibody SAE-1 & $2 / 1$ & $0 / 0$ & - \\
\hline Antibody NXP-2 & $2 / 11$ & $2 / 5$ & 0.907 \\
\hline Other antibody negative & $12 / 0$ & $2 / 12$ & 0.000 \\
\hline
\end{tabular}

The CT score of ILD in 153 DM patients stratified by Ro-52 antibody

The HRCT score reflected the severity of ILD. We evaluated and graded the CT scores of all the 153 DM cases and found that in both Ro-52 negative and positive groups, most cases were at the minor change of ILD ( $69.4 \%$ and $71.6 \%$, respectively). Moreover, the CT scores were significantly higher for the Ro-52 positive group than those for the negative group in the minor change ILD cases ( $P=0.000)$, while no 
significant difference was observed in the moderate change $(P=0.037)$ and severe change of ILD $(P=$ 0.876). According to the statistics of count data, the ILD severity of the Ro-52-positive group was significantly higher than that of the Ro-52-negative group $(P=0.000)$ (Table 4) .

Table 4

The CT score of ILD in 153 DM patients stratified by Ro-52 antibody

\begin{tabular}{|llll|}
\hline Patient Characteristic & Ro-52 antibody & P-value \\
\hline Total(N = 153) & Negative(N = 72) & Positive(N=81) & \\
\hline Lung HRCT status & & & 0.000 \\
\hline Normal HRCT, $n(\%)$ & $18(25.0 \%)$ & $11(3.7 \%)$ & \\
\hline High resolution CT score = & 0 & 0 & 1.000 \\
\hline ILD: minor change, $n(\%)$ & $50(69.4 \%)$ & $50(71.6 \%)$ & \\
\hline High resolution CT score(0-1), mean (S.D.) & $0.088 \pm 0.11$ & $0.293 \pm 0.212$ & 0.000 \\
\hline ILD: moderate change, $n(\%)$ & $2(2.8 \%)$ & $16(19.8 \%)$ & \\
\hline High resolution CT score(1-3), mean (S.D.) & $1.233 \pm 0.141$ & $1.650 \pm 0.622$ & 0.370 \\
\hline ILD: severe change, $n(\%)$ & $2(2.8 \%)$ & $4(4.9 \%)$ & \\
\hline High resolution CT score(3-6), mean (S.D.) & $4.392 \pm 1.355$ & $4.262 \pm 0.675$ & 0.876 \\
\hline
\end{tabular}

\section{Discussion}

With the development of the Rheumatology and Immunology Department in large hospitals in China, the types of connective tissue diseases that are referred to the dermatology department have changed. Patients with DM accompanied by skin manifestations are now increasingly first referred to dermatology. In China, the largest hospitals have begun to fully screen MSAs and MAAs for DM patients since 2016; hence, this study retrospectively analyzed the records of 153 inpatients with DM from March 1, 2016 to September 30,2019. We analyzed the positive rate of MSAs and MAAs, collected the data on the incidence of ILD, screened for cancer, calculated the HRCT score, and analyzed the relationship between the MSAs, MAAs, and ILD.

We found that antibodies MDA5 were risk factors for ILD formation. Our data showed that $36(23.5 \%)$ of the 153 DM patients expressed antibody MDA-5, and 27 out of these 36 patients had ILD. The MDA5 antibody is often associated with rapidly progressive ILD, as has been confirmed by previous studies [11]. Also, our data showed the CT scores of MDA5 positive DM patients were higher than the negative group (This part of the results were not show). Previous studies have found that antibodies Jo-1 and PL-7 are the two showing the highest positive rate in the aminoacyl-trans-fer RNA synthetase antibody of DM. Furthermore, the positive rate in patients with DM is less than $10 \%$ [12-14]. Our data also showed that 
the positive rates of antibodies Jo- 1 and PL-7 were $9.2 \%$ and $8.5 \%$, and 10 out of 14 patients had ILD for the Jo-1 positive group and 8 out of 13 patients had ILD for the PL-7 positive group, respectively. However, the positive rates of the other histidyl-transfer ( $\mathrm{t}$ )RNA synthetase antibodies were relatively lower, such as antibodies PL-12, EJ, and OJ, which were $2.6 \%, 3.9 \%$, and $1.3 \%$, respectively, similar to previous reports [15]. Six cases of DM patients expressed with EJ antibody, all of six patients had ILD. Thus, the suggestive effect of antibody EJ on ILD is noteworthy in DM.

We found that 81 (52.9\%) of the 153 DM patients were positive for Ro-52, which had the highest rate of occurrence among all sixteen antibodies tested, 14 (9.2\%) were only Ro-52-positive. These results are different to those from a previous study, where nearly $20 \%$ of the IIM patients only expressed the Ro-52 antibody [16]. In our study, we found that 70 (86.4\%) of the 81 Ro-52-positive patients had ILD; 12 (85.7\%) of 14 only Ro-52-positive patients had ILD. Whether or not Ro-52 antibody is combined with other antibodies, the probability of ILD was similar. The ratio of ILD was significantly higher in the Ro-52positive than in the antibody-negative patients (15.3\%). A total of $82.7 \%$ of the patients expressed Ro-52 combined with other antibodies, our study showed that Ro-52 increased the incidence of ILD when combined with other antibodies PM-Scl75, PM-Scl100, TIF1- $\gamma$, Mi-2 $\beta$ and MDA5. Evaluation of the CT scores of all the 153 patients showed that the ILD scores were higher for the Ro-52-positive cases than those for the Ro-52-negative cases only in the minor change ILD group. Meanwhile, in the moderate and severe change ILD groups, the number of Ro-52-positive patients was more than those in the Ro-52negative group, whereas, there was no significant difference in the CT scores between both the groups. Taken together, the overall severity of ILD was higher in the Ro-52 group than that in the non-Ro-52 group. These results suggest that Ro-52 is a risk factor for ILD in DM.

Ro-52 was a previously neglected antibody in DM patients. The Ro family consists of the SSA/Ro antibody, SSB/La antibody (48 KDa), and Calreticulin. SSA (Ro) antigens include two proteins, with molecular weights of $52 \mathrm{kDa}$ (anti-Ro-52) and $60 \mathrm{kDa}$ (anti-Ro-60) [17]. Previous studies have shown that antibody Ro-52, involved in transcription regulation, displays pathogenicity but lacks specificity, and could appear in many connective tissue diseases [18]. This antibody can cause lupus and atrioventricular blockage in neonates through the placental barrier [19]. Another study found that the occurrence of Ro-52 in patients with Sjogren's syndrome was $75 \%$, but the specific mechanism of the antibody involved in the pathogenesis of Sjogren's syndrome is unknown [20]. A nationwide cross-sectional study in Norway suggested that anti Ro-52 was significantly associated with the occurrence of pulmonary fibrosis in mixed connective-tissue disease; thus, anti Ro- 52 can also be used as an indicator for predicting the occurrence of ILD [21]. A recent report showed that the Ro-52 antibody is related to pulmonary fibrosis DM in children, and to the severity of the disease [8]. However, the severity of DM is difficult to evaluate as systemic and opportunistic infections in DM patients have become a major influencing factor in DM prognosis, rather than only associated with malignant tumor or ILD [1]. Another study found that six DM cases with isolated anti-Ro-52 in DM rapidly developed progressive ILD, but the patients responded well to therapy and had good prognosis in DM [22]. Our data showed that patients with rapidly progressive ILD expressed antibody MDA5 or antibody MDA5 combined with antibody Ro-52. Therefore, we speculate 
that Ro-52 is a specific antibody for ILD, regardless of the type of connective tissue disease. However, this conjecture needs to be verified by further clinical studies of connective tissue disease.

\section{Conclusion}

Our data showed that antibody Ro-52 is the most commonly occurring (52.9\%) antibody in DM patients. The presence of Ro-52 in DM patients strongly suggests the possibility of the occurrence of ILD (86.4\%). The severity of Ro-52-positive cases is higher than that of the Ro-52-negative cases. Hence, antibody Ro52 is a risk factor for ILD in DM. Meanwhile, Ro-52 may increase the incidence of ILD when combined with other antibodies PM-Scl75, PM-Scl100, TIF1- $\gamma$, Mi-2 $\beta$ and MDA5. The above conjecture needs to be verified by data obtained by studying larger cohorts, and long-term patient follow-up.

\section{Abbreviations}

ILD: Interstitial lung disease; DM: Dermatomyositis; MSAs: myositis-specific autoantibodies; MAAs: myositis-associated autoantibodies; HRCT: High-resolution computed tomography; anti-TIF1- $\gamma$ : antibody human transcription intermediary factor $1 \gamma$; Anti-MDA5: Anti-melanoma differentiation-related gene 5; PET-CT: positron emission tomography-computed tomography; LDH: lactate dehydrogenase; CK: creatine kinase ;

\section{Declarations}

\section{Acknowledgements}

We thank Dr. Chuncai Luo and Dr. Song Wang冈lmaging Department, PLA General Hospital, Beijing, for assistance in the score of HRCT.

\section{Authors' contributions}

Anqi Li contributed to the data collection, interpretation of results; Xiaojing Xing contributed to study design, data analysis, preparation of the manuscript. Yonghong Hao contributed to the polish the language of manuscript; Chengxin Li contributed to revision over the manuscript. All authors have read and approved the final manuscript.

\section{Funding}

No funding supported for this study.

\section{Ethics approval and consent to participate}

Written consent from all patients was obtained prior to study commencement. Ethical approval from all participating hospitals was obtained prior to study commencement. 


\section{Consent for publication}

All data used in this study has obtained patient consent for publication. All authors have read and approved this manuscript.

\section{Competing interests}

The authors declare that they have no competing interests.

\section{References}

1. Ren Z, Laumann AE, Silverberg JI. Association of dermatomyositis with systemic and opportunistic infections in the United States. Arch Dermatol Res. 2019;311(5):377-387.

2. Long K, Danoff SK. Interstitial Lung Disease in Polymyositis and Dermatomyositis . Pulmonary manifestations of polymyositis/dermatomyositis. Clin Chest Med. 2019;40(3):561-572.

3. Eri W, Takahisa G, Masataka K and Chihiro T. Predictive factors for sustained remission with stratification by myositis-specific autoantibodies in adult polymyositis/ dermatomyositis. Rheumatology (Oxford). 2019 Aug 13. pii: kez328.

4. Hida A, Yamashita T, Hosono Y, Inoue M, Kaida K, Kadoya M, Miwa Y, Yajima N, Maezawa R, Arai S, Kurasawa K. Anti-TIF1-gamma antibody and cancer-associated myositis: a clinicohistopathologic study. Neurology. 2016,19;87(3):299-308.

5. Fiorentino DF, Kuo K, Chung L, Zaba L, Li S, Casciola-Rosen L. Distinctive cutaneous and systemic features associated with antitranscriptional intermediary factor- $1 y$ antibodies in adults with dermatomyositis. J Am Acad Dermatol. 2015;72(3):449-55.

6. Abe Y, Matsushita M, Tada K, Yamaji K, Takasaki Y, Tamura N. Clinical characteristics and change in the antibody titres of patients with anti-MDA5 antibody-positive inflammatory myositis. Rheumatology. 2017, 56(9): 1492-1497.

7. Hallowell RW $\otimes$ Danoff SK. Interstitial lung disease associated with the idiopathic inflammatory myopathies and the anti-synthetase syndrome : recent advances. Curr Opin Rheumatol. 2014,26(6):684-689.

8. Sabbagh S, Pinal-Fernandez I, Kishi T, Targoff IN, Miller FW, Rider LG, Mammen AL. Anti-Ro52 autoantibodies are associated with interstitial lung disease and more severe disease in patients with juvenile myositis. Ann Rheum Dis. 2019,78(7):988-995.

9. Lundberg IE, Tjärnlund A, Bottai M, Werth VP, Pilkington C, Visser M, Alfredsson L, Amato AA, Barohn RJ. 2017 European League Against Rheumatism/American College of Rheumatology Classification Criteria for Adult and Juvenile Idiopathic Inflammatory Myopathies and Their Major Subgroups. Arthritis Rheumatol. 2017,69 (12): 2271-2282. 
10. Fujimoto K, Taniguchi H, Johkoh T, Kondoh Y, Ichikado K, Sumikawa H, Ogura T, Kataoka K, Endo T, Kawaguchi A. Acute exacerbation of idiopathic pulmonary fibrosis: high-resolution CT scores predict mortality. Eur Radiol. 2012;22(1):83-92.

11. Moghadam-Kia S, Oddis CV, Sato S, Kuwana M, Aggarwal R. Anti-Melanoma DifferentiationAssociated Gene 5 Is Associated With Rapidly Progressive Lung Disease and Poor Survival in US Patients With Amyopathic and Myopathic Dermatomyositis. Arthritis care \& research. 2016, 68(5): 689-694.

12. Nishikai M, Reichlin M. Heterogeneity of precipitating antibodies in polymyositis and dermatomyositis. Characterization of the Jo- 1 antibody system. Arthritis \& Rheumatology.1980;23(8):881-8.

13. Liu H, Xie S, Liang T, Ma L, Sun H, Dai H, Wang C. Prognostic factors of interstitial lung disease progression at sequential HRCT in anti-synthetase syndrome. Eur Radiol. 2019;29(10):53495357.

14. Pinal-Fernandez I, Casal-Dominguez M, Huapaya JA, Albayda J, Paik JJ, Johnson C, Silhan L, Christopher-Stine L. A longitudinal cohort study of the anti-synthetase syndrome: increased severity of interstitial lung disease in black patients and patients with anti-PL7 and anti-PL12 autoantibodies. Rheumatology. 2017;56(6):999-1007.

15. Marie I, Josse S, Decaux O, Dominique S, Diot E, Landron C, Roblot P, Jouneau S, Hatron PY, Tiev KP, Vittecoq O, Noel D, Mouthon L, Menard JF, Jouen F. Comparison of long-term outcome between anti-Jo1- and anti-PL7/ PL12 positive patients with anti-synthetase syndrome. Autoimmun Rev. 2012;11(10):739-45.

16. Yoshimi R, Ueda A, Ozato K, Ishigatsubo Y. Clinical and pathological roles of Ro/SSA autoantibody system. Clin Dev Immunol. 2012;2012:606195.

17. Salomonsson S, Dzikaite V, Zeffer E, Eliasson H, Ambrosi A, Bergman G, Fernlund E, Theander E, Ohman A, Rydberg A, Skogh T, Wållberg-Jonsson S, Elfving A, Fored M, Ekbom A, Lundström U, Mellander M, Winqvist O, Sonesson SE, Gadler F, Jonzon A, Wahren-Herlenius M. A Populationbased Investigation of the Autoantibody Profile in Mothers of Children with Atrioventricular Block. Scand J Immunol.2011;74(5):511-7.

18. Dugar M, Cox S, Limaye V, Gordon TP, Roberts-Thomson PJ. Diagnostic utility of anti - Ro52 detection in systemic autoimmunity. Postgrad Med J. 2010;86(1012):79-82.

19. Salomonsson S, Sonesson SE, Ottosson L. Ro/SSA autoantibody directly bind cardiomyocytes, disturb calcium homeostasis, and mediatecongenital heart block. J Exp Med. 2005,201(1):11-17.

20. Shiboski SC, Shiboski CH, Criswell L, Baer A, Challacombe S, Lanfranchi H, Schiødt M, Umehara H, Vivino F. American College of Rheumatology classification criteria for Sjögren's syndrome: a datadriven, expert consensus approach in the Sjögren's International Collaborative Clinical Alliance cohort. Arthritis Care Res.2012; 64: 475-87.

21. Gunnarsson R, El-Hage F, Aaløkken TM , Reiseter S , Lund MB , Garen T. Associations between antiRo52 antibodies and lung fibrosis in mixed connective tissue disease. Rheumatology (Oxford). 
2016;55(1):103-8.

22. Ohashi K, Sada KE, Nakai Y, Matsushima S , Asano Y, Hayashi K, Yamamura Y, Hiramatsu $S$, Miyawaki $Y$, Morishita M , Katsuyama T , Katsuyama E, Watanabe H, Tatebe N , Narazaki $M$, Matsumoto $Y$, Sunahori Watanabe K, Kawabata T , Wada J . Cluster Analysis Using AntiAminoacyl-tRNA Synthetases and SS-A/Ro52 antibodies in Patients With Polymyositis/Dermatomyositis. J Clin Rheumatol.2019;25(6):246-251. 2019;25(6):246-251. 